\title{
Census Ethnobotanical Study of Some Plants Used in Traditional Medicine in the City of Meknes
}

\author{
Fadila Moussaoui ${ }^{1}$, Tajelmolk Alaoui ${ }^{1}$, Saadia Aoudry ${ }^{2}$ \\ ${ }^{1}$ Department of Biology, Laboratory of Environment and Health, Faculty of Sciences, Moulay Ismail University, \\ Meknes, Morocco \\ ${ }^{2}$ Department of Plant Protection and Environment, ENA, Meknes, Morocco \\ Email: moussaoui.fadila@gmail.com
}

Received 6 May 2014; revised 19 June 2014; accepted 25 July 2014

Copyright (C) 2014 by authors and Scientific Research Publishing Inc.

This work is licensed under the Creative Commons Attribution International License (CC BY). http://creativecommons.org/licenses/by/4.0/

(c) (i) Open Access

\begin{abstract}
An ethnobotanical survey was conducted in the city of Meknès over a period of two years, from 2009 to 2011 with 1000 people (615 women, 385 men). Through the questionnaire, schedules were established to collect information on the use of therapeutic medicinal plants by the local population. This research has focused primarily on the general population, herbalists and healers. The present investigation has enumerated 194 species distributed in 165 genera and 72 families. The most represented families are Lamiaceae (18\%), the Aseraceae, $(17 \%)$, the Apiaceae (14\%) and the Fabaceae $(10 \%)$. The results of the survey show that $54 \%$ of individuals use both herbal medicine and modern medicine, $26 \%$ of individuals use herbs and $20 \%$ use modern medicine. We are interested in the use of plants in different ages and sexes. We report that $31 \%$ of the population is aged between 51 and 60 years, $29 \%$ between 41 and 50 years, $23 \%$ between 31 and 40 years, $10 \%$ between 21 and 30 years, $3 \%$ less than 20 years and $4 \%>60$ years. We note the predominance of women over men. Women use up to $61 \%$ against $39 \%$ of men. The analysis of our results shows that herbal medicine takes a place in the self-medication of the population studied. However, we emphasize an important point: Ignorance of toxic plants, in fact, only $19 \%$ of the target population recognizes these plants.
\end{abstract}

\section{Keywords}

Ethnobotanical Survey, Medicinal Plants, Traditional Use, Toxic Plants

\section{Introduction}

In recent decades, the use of medicinal plants has grown considerably. In this regard, the human pharmacopoeia

How to cite this paper: Moussaoui, F., Alaoui, T. and Aoudry, S. (2014) Census Ethnobotanical Study of Some Plants Used in Traditional Medicine in the City of Meknes. American Journal of Plant Sciences, 5, 2480-2496. 
has a rich repertoire of no less than 20,000 species of which 50\% are widely used in pharmaceutical industry [1]. The use of plants becomes daily in curative and preventive form [2]. Medicinal plants are valuable resources for the vast majority of the rural population in Africa [3]. According to the World Health Organization (WHO), more than $80 \%$ of African people resort to traditional medicine and pharmacopoeia to overcome many health problems [4].

Indeed, traditional medicine remains widespread in developing countries. In this context, Morocco remains one of the Mediterranean countries that have a long medical tradition and a traditional herbal [5] expertise. Because its geographical location, Morocco enjoys a natural setting quite original promoting a rich and varied flora. Of the 7000 species and subspecies existing, 537 are endemic to the country, and 1625 are rare or endangered [6]. Meknès-Tafilalet by its Mediterranean climate and its geographical features has favorable conditions for the development of a rich and varied flora plants with medicinal properties. This study of medicinal plants in the region will allow the public to know them better and therefore to use them better. This study is a contribution to the preservation of botanical heritage of the region.

\section{Methodology}

\subsection{Situation of the Study Zone}

The city of Meknes covers a surface of 178,700 Ha. It is bordered to the north by the Province of Sidi Kacem, on the West by the Province of Khémisset, on the South by the Province of El Hajeb and in the East by Zouagha Moulay Yaakoub [7]. Crop production is characterized by a large interannual variability related mainly to climatic conditions; particularly drought that has become structural, sometimes hail and wish Chergui (rising temperatures in the spring). The climate of the area (latitude, $33^{\circ} 53^{\prime} 36^{\prime \prime} \mathrm{N}$, longitude $5^{\circ} 32^{\prime} 50^{\prime \prime} \mathrm{W}$, altitude $548 \mathrm{~m}$ ) [8] is temperate Mediterranean type understory undergoing continental influences during the summer and winter season.

However, the geographical diversity of the region that each of its natural areas presents particular climatic nuances. During the year, the distribution of rainfall is characterized by heavy rains in autumn, a slight decrease in winter with a relative increase in early spring. Summer is generally dry. Rainwater seeping in reliefs of Atlas average plateau in dolomitic limestones of the Lias powered groundwater. These waters create a free web in the first plateau and along the plain of Meknes-Fez, which then sinks beneath the impermeable ground tertiary and so is the deep confined aquifer in the plain [7]. Surface waters are represented by two main namely networks: Oued R'DOM and network Oued Mikkes. The total population of the prefecture of Meknes amounts to 713,609 inhabitants. This is one of the most populated areas of the Kingdom (340 inhabitants $/ \mathrm{km}^{2}$ ). The rural population represents $20 \%$ of the total population of the prefecture against $80 \%$ in urban areas. The illiteracy rate is much higher in rural areas than in urban areas with inter-gender disproportions: the rate is $43.8 \%$ among women and 22\% among men [7] (Figure 1).

\subsection{Questionnaire}

We conducted an ethnobotanical survey in the various districts of the city of Meknes to collect as much information on medicinal plants used.

Our investigation was spread over a period of 2 years (2009-2010 and 2010-2011), during this period, we have achieved 1000 interviews with people of both sexes. We have identified 194 medicinal plants used by local people in traditional medicine and inventory 133 recipes.

This survey was conducted using two questionnaires records:

-A card sent to the questionnaire herbalists and healers.

-A survey form sent to users (consumers).

Through these questionnaires, we collected all the information regarding the questioned population (age, sex, marital status, level of education...) and plants used in traditional recipes (common identity, part of the plant used, method of preparation, therapeutic and traditional uses, effects, observed and/or expected...).

We present the results obtained regarding the traditional use of medicinal plants, after a comprehensive analysis of data collected over two years and with a data processing by the statistical software SPSS.

\section{Results and Discussion}

\subsection{Use of Medicinal Plants by Age}

Age between the (41 - 50) and (51 - 60) slices represent the highest percentage of users of plants. This use seems 
almost non-existent in the age group under 20 years and over 60 years (Figure 2). For young people, this choice could be justified by the lack of information on the importance of plants and also by the lack of confidence in the curative efficacy of traditional medicine. The use of plants is decreasing in the age group over 60 years. This observation could be explained by the fact that the diseases that occur at this age can be complicated and may require extensive treatment.

The results show that medicinal plants are used by almost all age groups. Similar results were observed by [9]-[13]

\subsection{Use of Medicinal Plants by Sex}

The results show that women use medicinal plants (61\%) more than men (39\%). Since the era of the time,

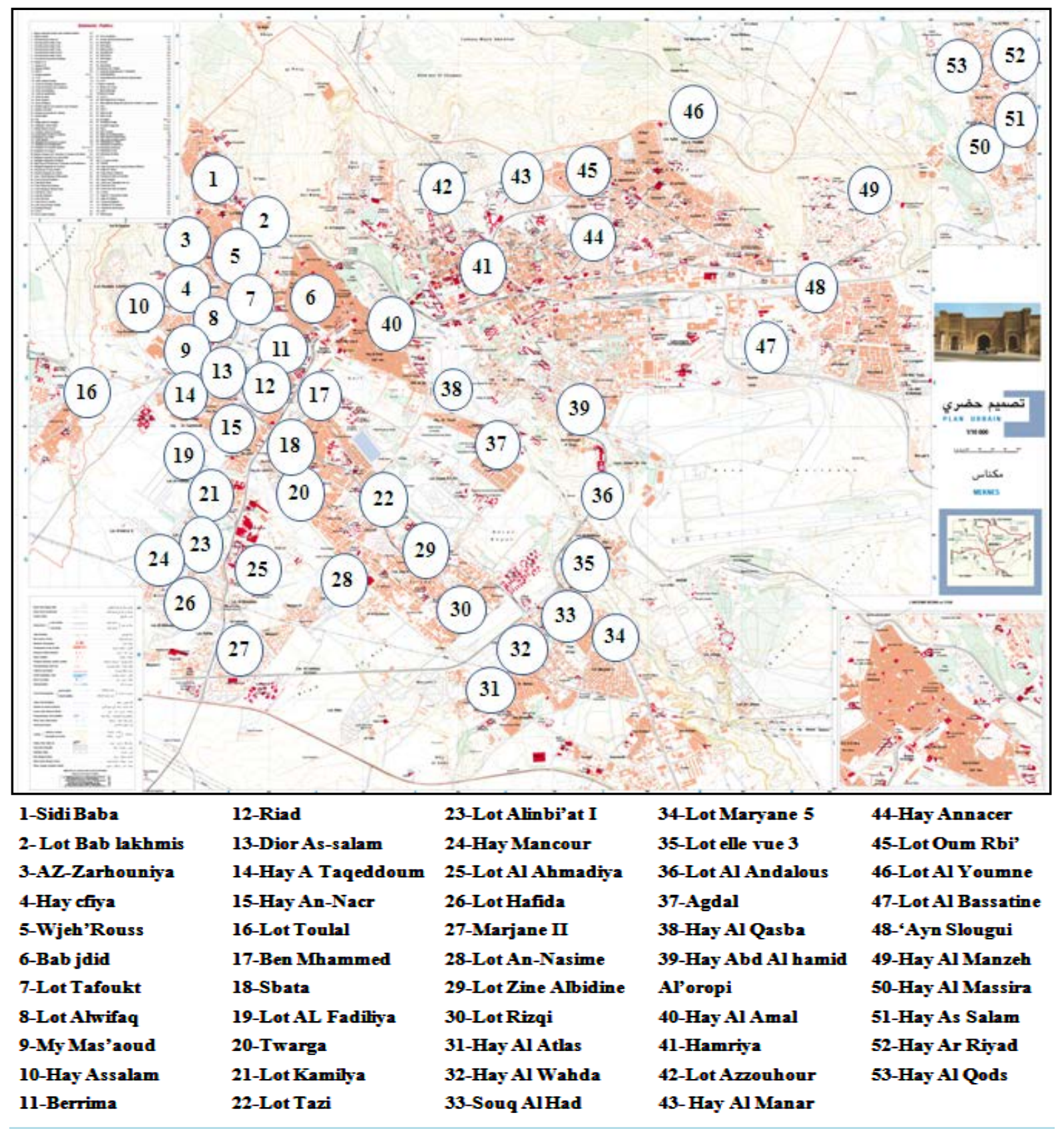

Figure 1. Distribution of ethnobotanical surveys point made in the city of Meknes. 
women were interested in plants for medicinal and cosmetic purposes. Their use is acquired following an accumulated knowledge and passed from one generation to another. Women have become custodians of traditional phytotherapy who know much more than men. Note that similar results have been reported by other authors [9] [14] (Figure 3).

\subsection{Socio-Economic Level}

\subsubsection{Education}

Analysis of the results allowed us to distinguish $52 \%$ of the population using plants is illiterate. These results are consistent with the work of [13]. The remaining percentages represent the category of educated population up to 23\% (primary), 15\% (secondary), and 10\% (university) (Figure 4). Although traditional medicine has existed since time immemorial, it continues to be used and that over the last ten years its popularity has only increased [10].

\subsubsection{Use of Medicinal Plants by Family}

It turns out that married people with children increase the use of medicinal plants $72 \%$, against $28 \%$ for singles.

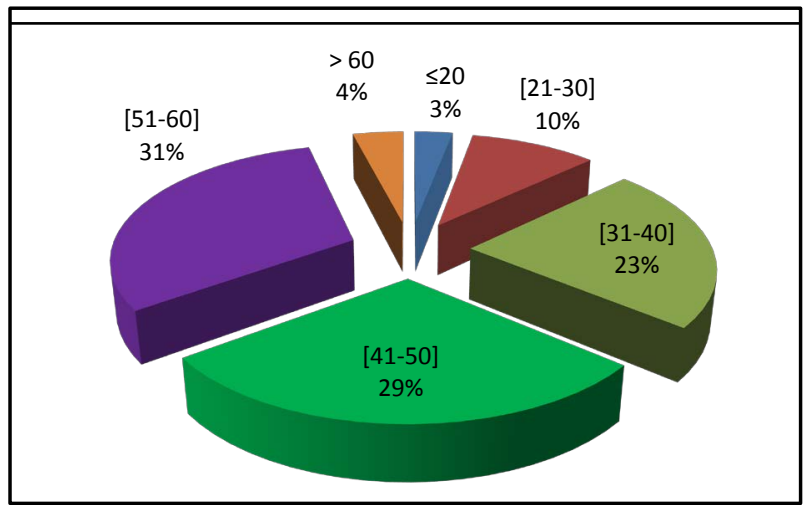

Figure 2. Frequency of use of medicinal plants by age.

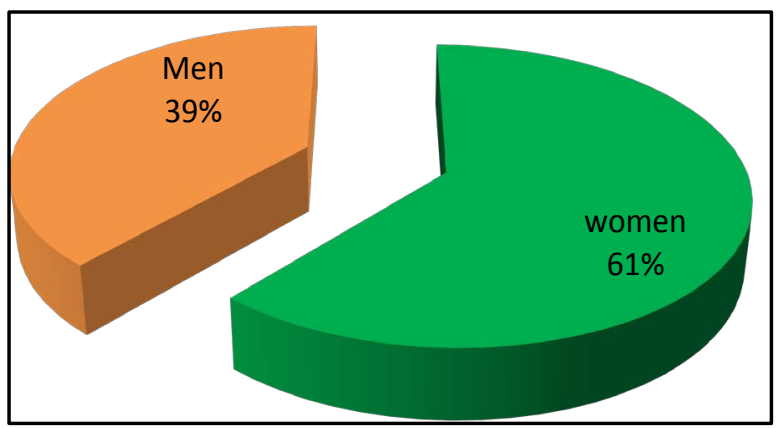

Figure 3. Frequency of use of medicinal plants by sex.

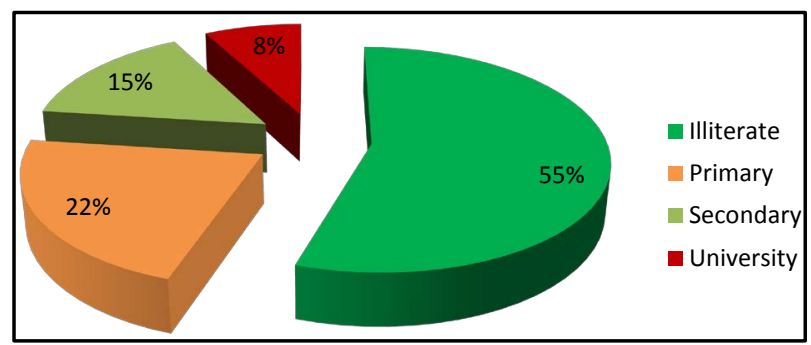

Figure 4. Frequency of use of medicinal plants by level of education. 
The same observation was reported by [13]. People with a family favor the use of medicinal plants. These plants remain in an environment suitable for all family members (Figure 5).

\subsubsection{Monthly income of those surveyed (in $\mathrm{dh}$ )}

From the results we can see that the category of illiterate population and that a monthly income of less than 1000 $\mathrm{dh}$, are more apt to medicinal plants. This could be explained by the low-cost plants in relation to drugs and the ease of preparation. For this category of the population, the possibility of self-medication is required (or prescription or medical examination) (Figure 6).

\subsection{First Visited in Case of Health Problem}

Of the 1000 people questioned in case of health problems, $26 \%$ of the population went first in the herbalist as a first alternative, $20 \%$ will visit a clinic or hospital, and $54 \%$ try to combine modern medicine and traditional medicine, probably for better efficiency (Figure 7).

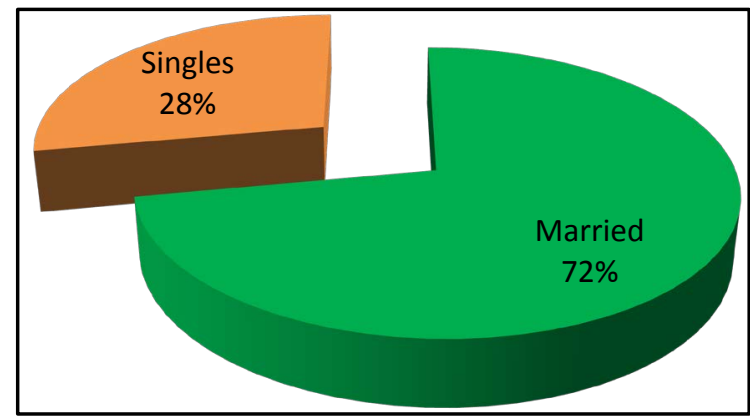

Figure 5. Frequency of use of medicinal plants by family.

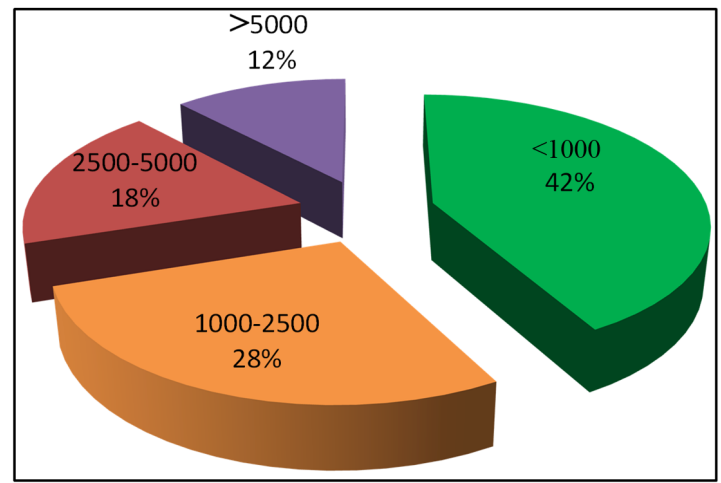

Figure 6. Monthly income of those surveyed (in dh).

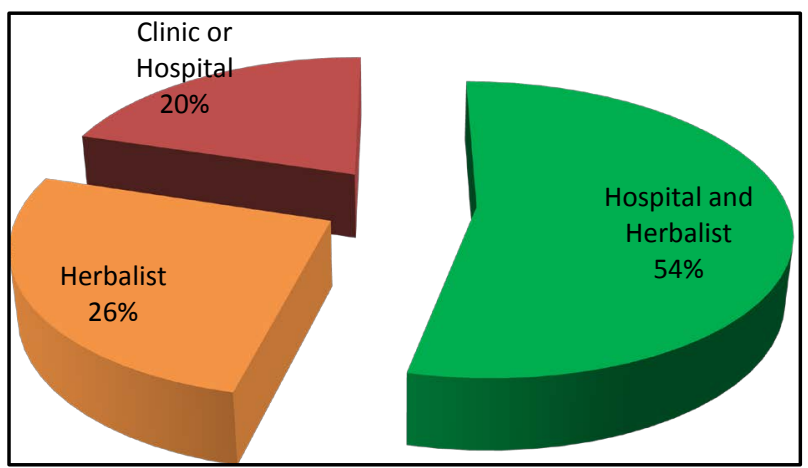

Figure 7. First visited by the public during a health problem. 


\subsection{Medicinal Plants Used in Treatment of Diseases}

\subsubsection{The Conditions Treated}

The population has questioned use herbs to relieve or cure ailments of the digestive tract (55\%), respiratory (20\%), genital tract (17\%), heart (3\%), rheumatic (3\%) and various ailments (visual, urinary, nervous) (2\%) (Figure 8).

\subsubsection{The Most Commonly Used Medicinal Plants}

The results show that the most used herbs by the population questioned are:

Origanum compactum benth, Thymus zygis L, Mentha pulegium L, Rosmarinus officinalis L, Artemisia herba-alba Asso, Lavandula angustifolia Miller, Cleome arabica L, Carum carvi L, Ajuga iva (L.) Schreb, Euphorbia officinalis $\mathbf{L}$, Foeniculum officinale. These plants are used in the composition of several recipes that treat certain diseases, such as diseases of the digestive tract, respiratory diseases, genital diseases, cardiovascular diseases, Rheumatic diseases, urinary diseases... (Figure 9).

\subsubsection{The Most Represented Families}

Our study has counted 194 species belonging to 165 genera and 72 families. The most represented families are Lamiaceae (18\%), the Asteraceae (17\%), the Apiaceae (14\%) and the Fabaceae (10\%)... (Figure 10).

\subsubsection{The Parts of the Plant Used}

The parts of the plant mainly used are the leaves (29\%), seeds (21\%), all of the aerial part (15\%) of the plant. Other parts of the plant (bark, root, stem, flower, seed and rhizome ...) are used occasionally. The study shows that the leaves are mostly used in the preparation of different recipes (Figure 11). The work Dibong (2011) and Benkhnigue (2011) reported similar findings.

Different parts of the same plant may have different chemical compositions and do not have the same action. The predominance of the use of a member with respect to another in the field of therapeutics derived from the

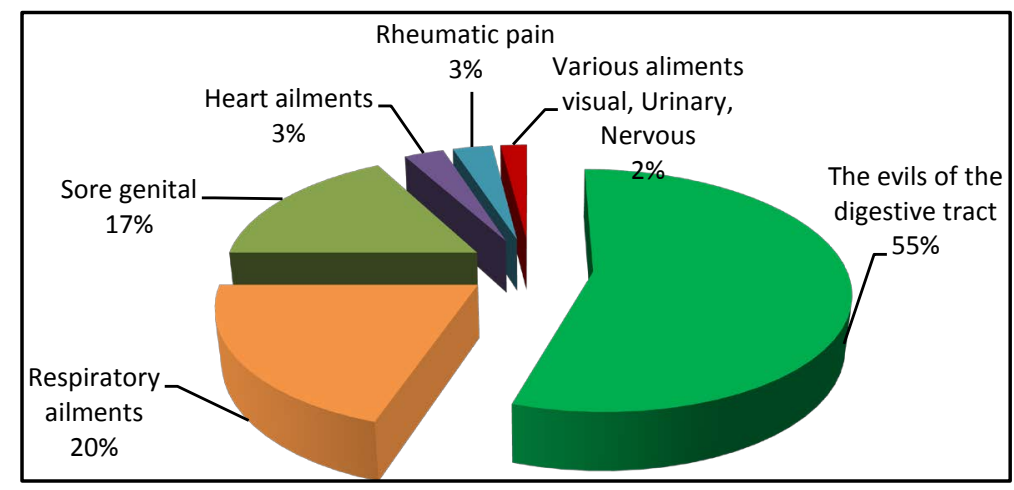

Figure 8. Representation of different conditions treated.

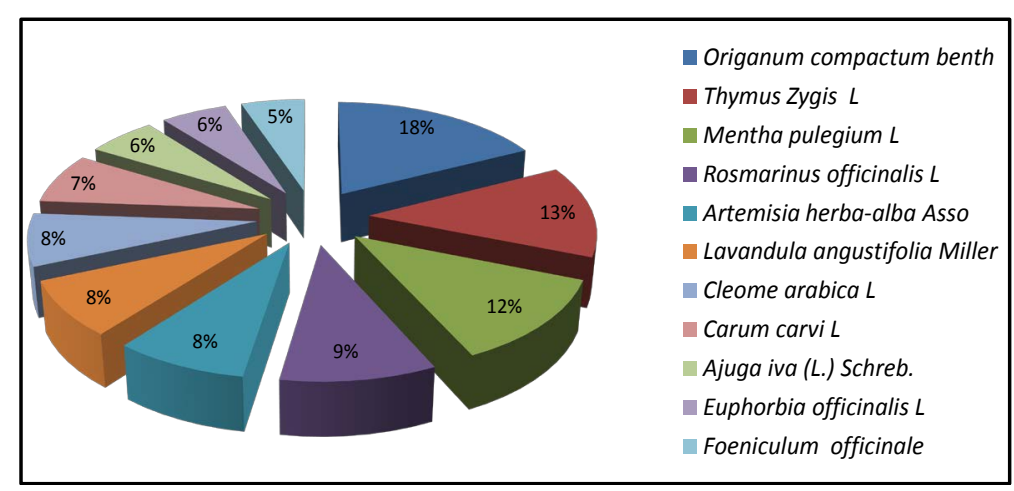

Figure 9. Medicinal plants most used by the population of the city Meknès. 


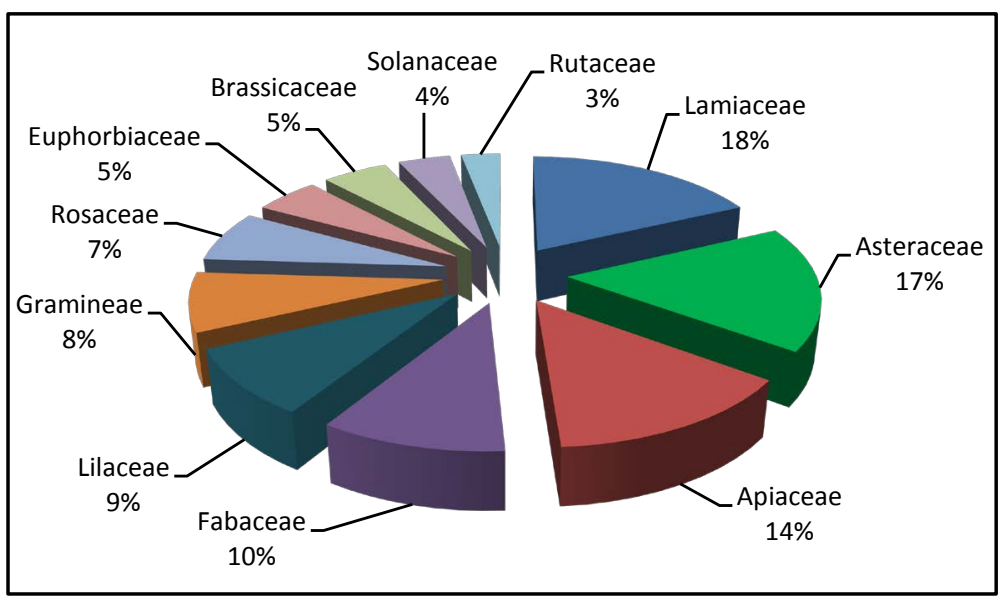

Figure 10. The most presented families.

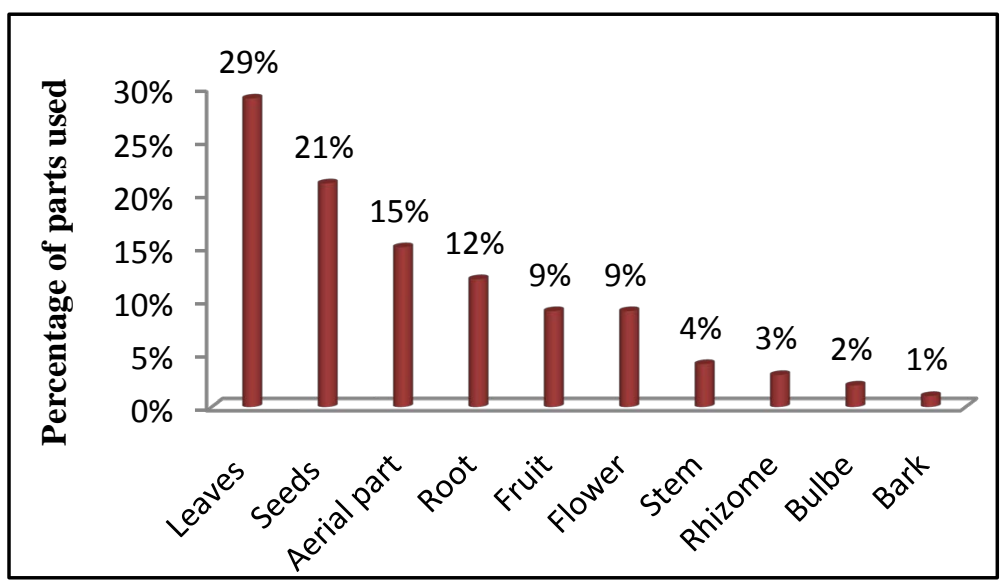

Figure 11. The parts of the plants used.

concentration of active ingredients in this organ [11]. Active principles can be found in all parts of the plant, but unevenly. And all the active ingredients in the same plant do not have the same properties [12]. The high use of the leaves can be explained by the fact that the leaves represent the organ specialized for photosynthesis. They are also the site of respiration and transpiration.

\subsubsection{Method of Preparation of Recipes}

Decoction is the main mode of preparation of (68\%). Other preparations, such as maceration (16\%), the powder (10\%), infusion (5\%) and the poultice (1\%), are also used (Figure 12). Other authors reported similar observations [4] [13].

According to the study, it appears that the oral route is the most recommended with a percentage of $60 \%$. However, other modes of administration by different routes are used as follows: externally (29\%), aural (5\%), ophthalmic (3\%) and nasal (3\%) (Figure 13).

\subsubsection{Features Recipes Identified}

The majority of the people questioned (86\%) used a single plant for the preparation of medicinal recipe (Figure 14). $14 \%$ of the population uses plants combined with ingredients from nature plant (82\%), or ingredients of animal and mineral in nature (18\%).

The nature of the ingredients varies depending on the mode of administration. The ingredients of mineral origin (sulfur, galena, rock salt), are dedicated for external use, while ingredients of animal origin such as milk, pieces of animal organs honey and even insects are for oral administration. 


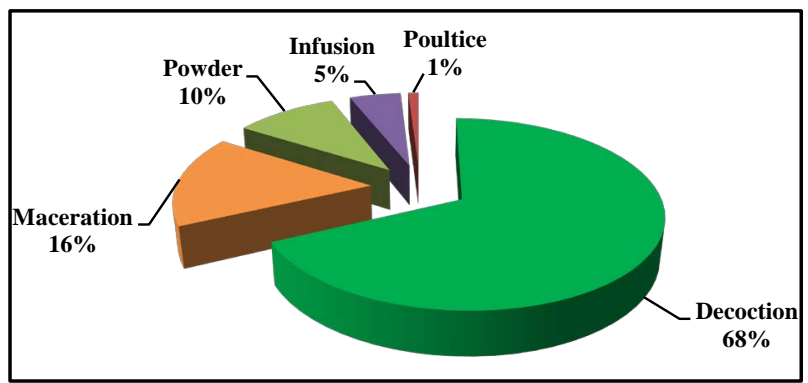

Figure 12. Methods of preparing recipes.

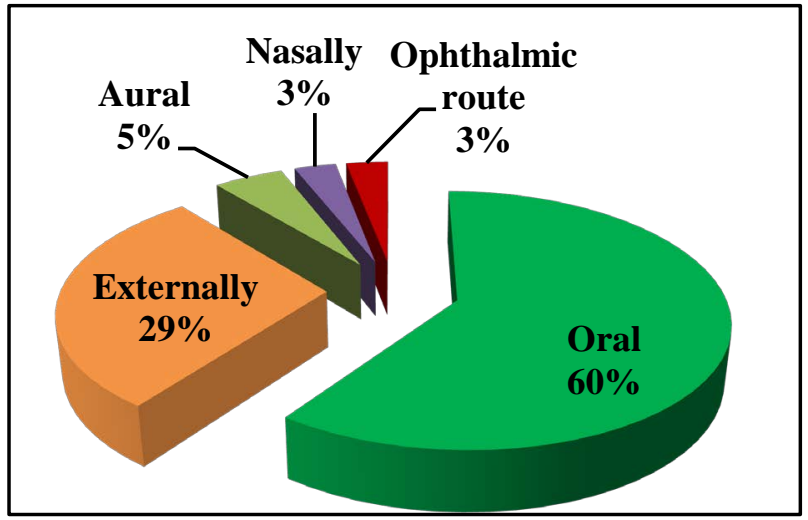

Figure 13. Modes of administration.

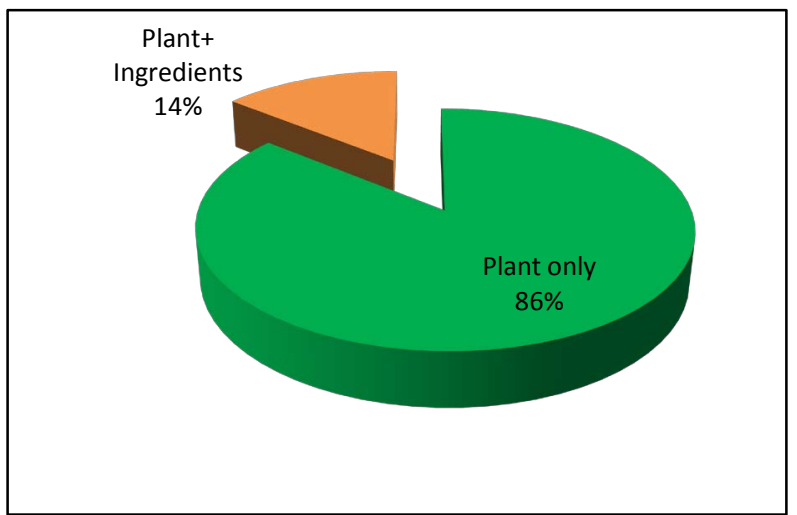

Figure 14. Features recipes identified.

\subsubsection{Source of Information Regarding the Therapeutic Use of Medicinal Plants}

The results showed that $56 \%$ of our respondents refer to the experiences of others to prepare recipes using medicinal plants, $20 \%$ of the population refer to herbalists, $18 \%$ of people following the media, while $6 \%$ people looking at books of traditional medicine. This result is consistent with the results obtained by (Benkhnigue, 2011) (Figure 15).

\subsection{Knowledge of Poisonous Plants}

The survey reveals that few people question (19\%) have knowledge about the toxicity of plants. This segment of the population is mostly older people who have some experience in the use of medicinal plants (Figure 16).

The rest of the population (81\%) said they had no information on toxic plants and the dangers they can cause to health. This population is more confidence in the herbalists. Identifying poisonous plants remains a crucial factor in the use of plants. 


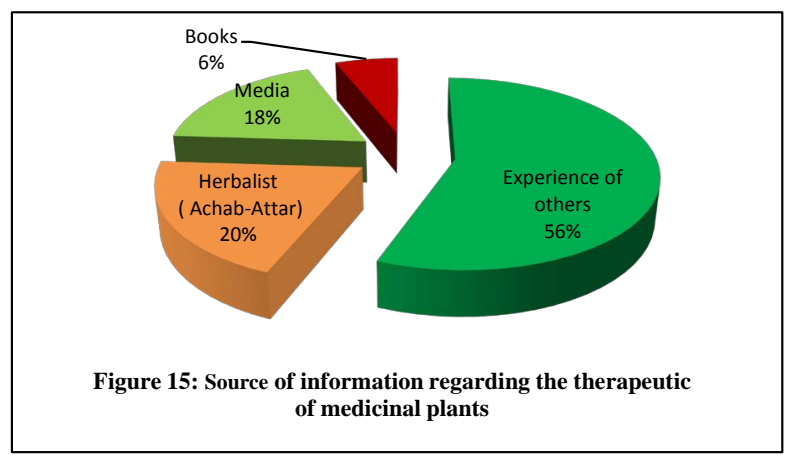

Figure 15. Source of information regarding the therapeutic use of medicinal plants.

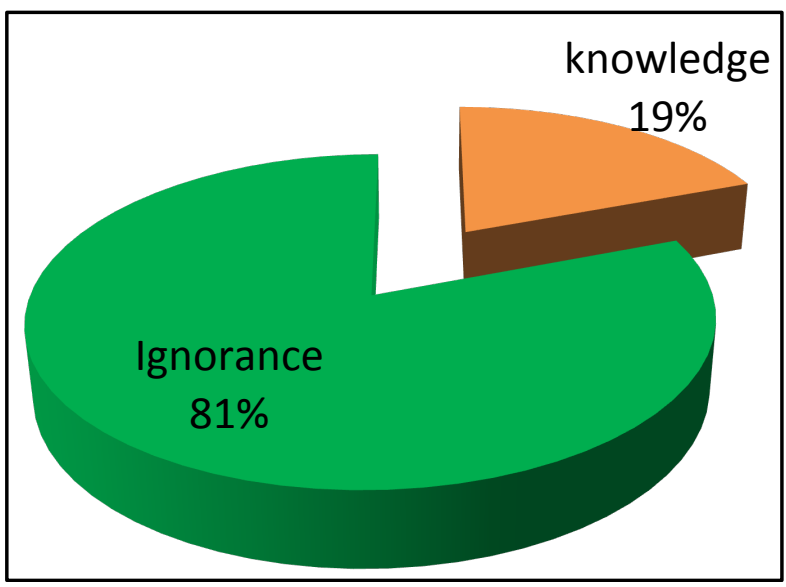

Figure 16. Distribution of the frequency of toxic plants knowledge.

Traditionally deemed safe and plants can be toxic when they are used on a large scale [15]. And plants may contain powerful chemicals, responsible for side effects and toxicity. Their use requires continuous vigilance [16].

The main plant has caused poisoning among the people of the city Meknes are listed in the Table 1.

Table 1. Plants that have caused poisoning in Meknes.

\begin{tabular}{cccc}
\hline Family & Scientific Name & French vernacular name & Local name \\
\hline Lamiaceae & Saliva officinalis $L$. & Sauge officinale & Salmiya (high doses) \\
Zigophylaceae & Peganum harmala $L$. & Harmel & El Hermel \\
Solanaceae & Datura stamonium $L$. & Datura & Chdak ejmel \\
Cucurbitaceae & Citrullus colocynthis $L$. & Coloquinte & Hdaj \\
Aristolochiaceae & Aristolochia longa $L$. & Aristoloche & Bereztem \\
Apocynaceae & Nerium oleander $L$. & Laurier rose & Defla \\
Liliaceae & Urginea scilla B. & Urginée fausse scille & Bassila \\
Cannabinaceae & Cannabis sativa $L$. & Chanvre & Kif \\
Papaveraceae & Papaver sommniferum $L$. & pavot & kharchacha \\
Asteraceae & Artemisia absinthium $L$. & Absinthe vraie & Chiba (high doses) \\
Astéraceae & Atractylis gummifera $L$. & Chardon à glu & Addad \\
\hline
\end{tabular}




\subsection{Treatment of Children by Plants}

Diseases are part of life and cannot be avoided despite all the advances in medicine [17].

Diseases affect also children. Herbal medication may be useful to treat or alleviate childhood ailments (diarrhea, constipation, cough, abdominal pain, colic....).

Many women prefer to care for their children without resorting to modern medicine. They know recipes using plants that are useful in the treatment of many problems faced by children since birth, these natural recipes from popular memory and proving highly effective in many years. These revenues continue to be transmitted from grandmothers to mothers and especially from woman to woman through time.

\subsubsection{Use of Herbal Medicines in Children}

In our study, 57\% of those surveyed opting for plants to treat their children. They prefer not to give medicines to their children for fear of side effects, while $43 \%$ of the targeted people tend to trust modern medicine (Figure 17).

Natural remedies will strengthen the natural defenses of the child to fight against various diseases. Plants can be highly effective and can help to protect the child.

\subsubsection{Age of Medicinal Plants Use in Children}

It appears from the survey results that $37 \%$ of women give their babies mixtures based on medicinal plants in the early days of birth (7 - 40 days). The plant most commonly used is Verbena officinalis, while $63 \%$ of women prefer to use plants from 6 months (Figure 18).

\subsubsection{The Plants Used to Treat Childhood Diseases}

The results obtained show that there are only a few types of plants which are suitable for children. Among the plants most commonly used are: Verbena officinalis L., Cumimum cyminum L., Origanum compactum benth, Mentha pulegium L., Lavandula angustifolia Miller, Foeniculum officinale, Artemisia herba-alba Asso, Carum carvi $L$., Thymus zygis $L$.

It appears that the Verbena officinalis $\mathbf{L}$. is widely used by mothers (46\%) (Figure 19). It is an aromatic plant popular infusion proposed to facilitate difficult digestion and in the symptomatic treatment of neurotonic conditions in adults and children [18]. It is also recommended in cases of fever, cough, and insomnia. It is recommended for children of all ages.

Cumimum cyminum L . comes with a percentage of $16 \%$ utilization to relieve abdominal pain, colic, indigestion, for both adults and children and even babies.

Mentha pulegium $\boldsymbol{L}$. is mainly used to aid digestion and fight against the spastic conditions in children.

Carum carvi $\mathbf{L}$. has many beneficial effects. It is frequently used to treat bronchitis and cough, particularly among children.

Foeniculum officinale is known for its ability to calm colic of children and babies. It is recommended in the case of digestive disorders and airway inflammation.

The Origanum spp. has a significant effect on the treatment of intestinal worms in children.

Artemisia herba-alba Asso helps to expel worms in the stomach, reduce phlegm and to eliminate colic.

Lavandula angustifolia Miller is used in particular in the treatment of pain and intestinal colic in children. Lavender is frequently used for its calming properties.

Thymus zygis $\mathbf{L}$. is considered the best treatment against coughs and expels worms in children.

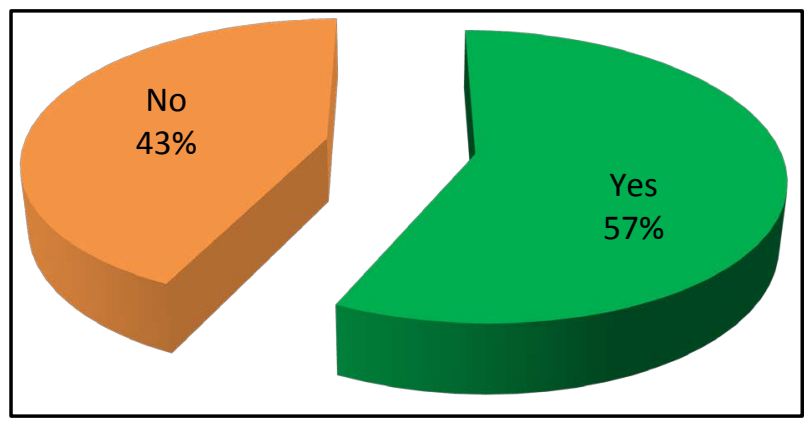

Figure 17. Use of herbal medicines in children. 


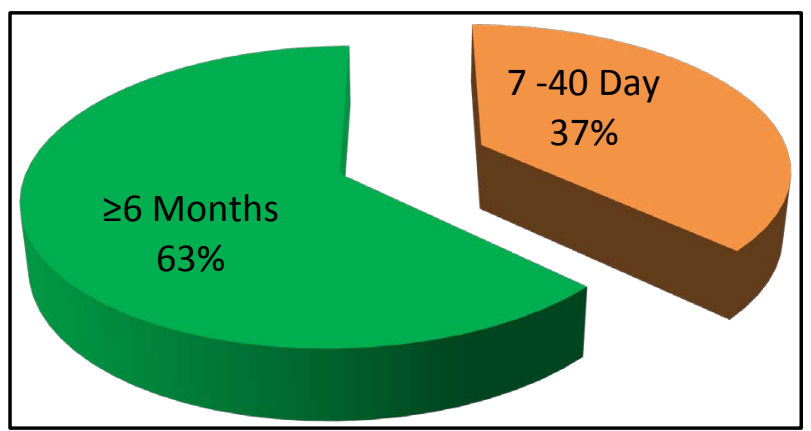

Figure 18. Age of medicinal plants use in children.

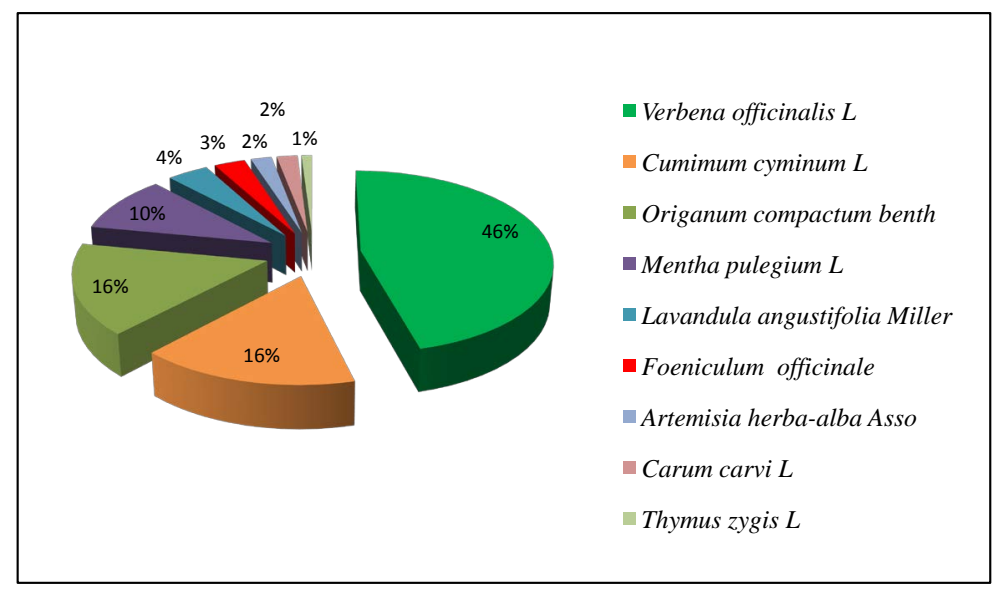

Figure 19. The plants to treat childhood disease.

\subsection{Herbalists and Healers}

The interview with healers and herbalists 20 moved to Meknes, which allowed us to collect a set of specific therapists and herbalists' such information.

\subsubsection{Healer}

Healer is a person who provides health care through the use of plant, animal, and mineral substances using personal recipes herbal. Healer heals the sick by empirical means: remedies or practices resulting from the experience. He knows the different properties of plants and their usefulness. The healer may also have personal resources that enable it to relieve pain and some infections, and reduce the types of fractures...

Unlike modern medicine, treatments healers are confidential and are not discussed openly. They can only be passed from generation to generation within the family healer [19].

Used by the healers to cure their sick methods are not always effective. Healers do not master the different diseases and do not fit the recipe and the proper dosage. Worse, some people develop other symptoms that can be severe (renal failure...).

\subsubsection{The Herbalist}

The herbalist is the most valuable source of information on medicines from plants. He is a plant specialist. His experience has been gained after a period of practice where along transmitted as a legacy of his ancestors. Knowledge of plants and their use to treat a particular condition is timeless. The work of the herbalist is based on experience and learning in a master or a family member doing the same job. Some herbalists update and improve their knowledge over time, others from reading books in the field.

The herbalist is not only a seller of medicinal plants but the professional capacity to recommend to his clients the use of plants. He can also make preparations with several plants according to the requirements that the client 
entrusts him. But in reality, most herbalists do not know the exact doses of the plants used. They do not give or give little information on the quantities. The method of preparation and the notion of quantity to interfere remain vague.

The herbalist collected plants either himself or buys from suppliers and farmers in the region and prepares the rest itself. Plants and their essences give excellent results for most diseases, but there are exceptions where herbal becomes useless as in the case of heavy diseases including cancers in an advanced state, cardiovascular diseases and genetic diseases...

Some plants have very many medicinal uses (such as Thymus vulgaris is good for all), while others are very specific to specific diseases (such as Citrullus colocynthis used for diabetes).

According to herbalists and healers, there are women-specific diseases (genital problems, menstrual cramps, hair loss, pain pregnancy and childbirth, skin problems...) and those that affect men (bladder problems, prostate, penile inflammation...).

\section{Conclusions}

The ethnobotanical survey we conducted allowed us to achieve a set of results for the characteristics of the target population and the therapeutic and traditional uses of medicinal plants identified. The analysis of our results shows that women use more than men medicinal plants.

Seniors know the therapeutic use of the medicinal plants than young, and this is due to a long experience acquired and passed from one generation to another.

The results also show that these are people with a family that uses more frequently than single medicinal plants.

$52 \%$ of people who use traditional medicine are illiterate. Diseases of the digestive tract are treated with a more obvious percentage of $55 \%$.

Botanically, the family is the most represented Lamiaceae (18\%). The leaves are the main parts of the most common plants. The most recognized method of preparation plant is decoction. The decoction is taken orally.

From the results obtained it was revealed that there was a lack of knowledge of poisonous plants. The random use of plants was a real danger for the user.

In the same vein, $57 \%$ of people choose to treat their children with herbal remedies, and at different ages.

\section{References}

[1] Bhar (2011) Aromatic and Medicinal Plants. These Fragrant Plants That Relieve Pain, 2nd Quarter, The Moroccan Space, No. 68.

[2] PRR (2007) Medicinal Plants. Share Knowledge for the Benefit of Rural Communities.

[3] Didier, D.S. (2011) Ethnobotany and Phytomedicine of Medicinal Plants in Douala. Journal of Applied Biosciences, 37, 2496-2507.

[4] Salhi, S., Fadli, M., Zidane, L. and Douira, A. (2010) Floristic and Ethnobotanical Studies of Medicinal Plants in the City of Kenitra (Morocco). Lazaroa, 31, 133-146. http://dx.doi.org/10.5209/rev_LAZA.2010.v31.9

[5] Scherrer, A.M., Motti, R. and Weckerle, C.S. (2005) Traditional Plant Use in the Areas of Monte Vesole and Ascea, Cilento National Park (Campania, Southern Italy). Journal of Ethnopharmacology, 97, 129-143. http://dx.doi.org/10.1016/j.jep.2004.11.002

[6] Benabid, A. (2000) Flora and Ecosystems Morocco, Evaluation and Conservation of Biodiversity. Ibis Press, Paris.

[7] PDA (2010) Monograph of the Action Area of the PDA Meknes. Provincial Directorate of Agriculture of Meknes.

[8] http://dateandtime.info/fr/citycoordinates.php?id=2542715

[9] El Rhaffari, L. and Zaid, A. (2002) Practice of Herbal Medicine in South-Eastern Morocco (Tafilalet). Empirical Knowledge for a Renovated Pharmacopoeia, Tafilalet.

[10] WHO (2000) General Guidelines for Methodologies on Research and Evaluation of Traditional Medicine. World Health Organization,Geneva.

[11] Didi, O., Hajj, M. and Zabeirou, H. (2003) Place Spontaneous in Traditional Medicine Area Ouargla (Northern Sahara EST) Plants. Faculty of Sciences and Engineering Sciences, University of Ouargla Algeria, No. 03, 47-51.

[12] Sebai, M. and Boudali, M. (2012) Phytotherapy between Trust and Mistrust. Algerian People’s Democratic Republic, Minister of Health, Population and Hospital Reform, Institute for Medical Training, CHETTIA. 
[13] Benkhnigue, O. (2011) Ethnobotanical Study of Medicinal Plants in the Region Mechraâ Bel Ksiri (Gharb Region of Morocco). Acta Bot, Barcelona, 191-216.

[14] Mehdioui, R. and Kahouadji, A. (2007) Study Ethnobotany with the Local Population of the Amsittène Forest: The Case of the Municipality of Imi n'Tlit (Province of Essaouira). Bulletin of the Scientific Institute, Rabat, Division of Life Sciences, No. 29, 11-20.

[15] Languedoc, R. (2007) The Risk of Medicinal Plants. Medical Antenna Preventing Doping (MAPD).

[16] Bencheikh, R.S. (2010) Plants and Public Health. Toxicology Morocco, 2nd Quarter, No. 5, 2.

[17] Regamey, N. and Frey, U. (2008) Pediatric Pulmonology. 3rd Edition, University Children’s Clinic, Berne.

[18] Mathieu, M. (2008) Manual Porphyry Pharmacy Technician. Part XIV Pharmacognosy, Wolters Kluwer, France.

[19] Müller, M. and Balagizi, I. (2001) Modern or Traditional Medicine: The Need for Cooperation. Quarterly Newsletter for Linking Development Workers Worldwide (Footsteps), No. 48. 


\section{Customer Questionnaire}

-Identification

sex:

Age:

Location:

-Family Location

Single:

Married:

Divorced:

Widower:

-Do you have children?

Yes

No

-Have you done any studies?

Yes

No

-If yes, what level did you reach?

Primary

Secondary

Superior

-When you have a health problem, who are you going to first?

Hospital:

Dispensary:

Herbalist

-What is your monthly income (dh)?

$<1000$

$2500-5000$

$1000-2500 \quad \square$
$>5000 \quad \square$

-If you go to the herbalist plants, you want and use them that you know in advance?

-What is the source of your information on the use of medicinal plants?

Experience of others

Digital
Herbalist (Achab-Attar)

Books 
-Is it you that happen to associate drugs with medicinal plants?

Yes

No

-If yes, in which case have you done?

-Have you had any health problems after following treatment with medicinal plants?

-If yes, which?

-Have you had positive results with treatment based on medicinal plants?

-Is it you that were satisfied with the use of medicinal plants? why?

-Do you use plants for your children?

Yes $\square$ No

-If yes, specify the age of your children, medicinal plants and the disease you have treated?

-Do you know the poisonous plants?

Yes

No

-Is there a knowledge transmitted in the family on the therapeutic use of medicinal plants? 


\section{Questionnaire to herbalists or healers}

-Identification

Sex:.

Age:

Location:.

-Do you have done training on the therapeutic use of medicinal plants?

-If yes, which?

-If not, who did you inherit your knowledge from?

-Do you read books?

-Do you refresh or do you improve your skills?

-What are the most traditionally used medicinal plants?

-These plants are used for what diseases, specify the part of the plant used, method of preparation and method of administration?

Disease:

Plant :

Part used:

Full

Root

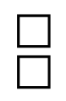

Upper

Grains

Leaves

Flower

-Method of Preparation

Infused

Décoctée

Macerated 
-Method of Administration

Oral $\square \quad$ Opthalmic $\square \quad$ Hearing

Outside

Nasal

-Are there dangerous diseases that can not be treated based on medicinal plants?

Yes

No

If yes, specify which:

-In your opinion, what are the reasons why people use medicinal plants?

Due to their cost

Due to their effectiveness

-Is it medicinal plants that are expensive me as pharmaceuticals?

-Are people aware of the therapeutic properties of medicinal plants?

-Is it an increase in demand for medicinal plants by the population?

Yes

No

Why

-Where do you obtain medicinal plants?

a) Directly nature

b) From supplier

d) The farmers in the region

-They are poisonous plants?

-What kinds of problems can they cause? 
Scientific Research Publishing (SCIRP) is one of the largest Open Access journal publishers. It is currently publishing more than 200 open access, online, peer-reviewed journals covering a wide range of academic disciplines. SCIRP serves the worldwide academic communities and contributes to the progress and application of science with its publication.

Other selected journals from SCIRP are listed as below. Submit your manuscript to us via either submit@scirp.org or Online Submission Portal.
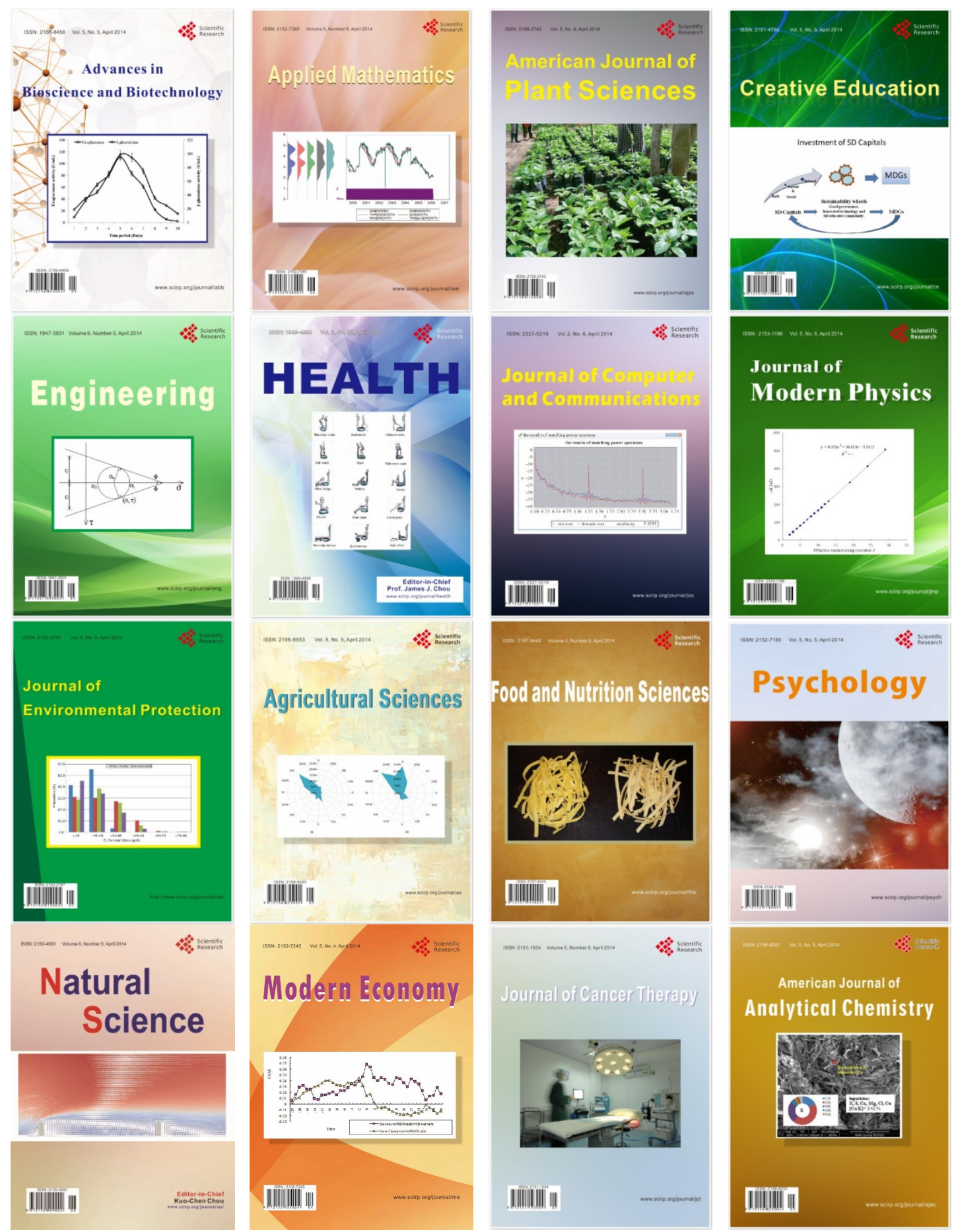